\title{
COMMENTARY
}

\section{Predicting treatment failure in severe sepsis and septic shock: looking for the Holy Grail}

Juan Carlos Ruiz-Rodríguez ${ }^{1,2^{*}}$ and Jordi Rello $0^{1,2,3}$

See related research by Schuetz et al., http://ccforum.com/content/17/3/R115

\begin{abstract}
Procalcitonin has been proposed as a specific biomarker of bacterial infections and has been related to the severity of sepsis. The prognostic ability of the initial concentrations of procalcitonin in sepsis is controversial. Some studies find higher initial concentrations in non-survivors but others find no differences. Prognostic assessment based on follow-up of procalcitonin levels may be better than evaluation of the initial levels of procalcitonin. The persistence of elevated procalcitonin levels is indicative of poor prognosis and is associated with mortality.

Procalcitonin kinetics could be a tool for assessing the evolution of severe sepsis and sepsis shock.

Procalcitonin should find its place as a biomarker for predicting treatment failure of severe sepsis and septic shock.
\end{abstract}

In the previous issue of Critical Care, Schuetz and colleagues [1] present further evidence about the usefulness of procalcitonin (PCT) for prognostic prediction in septic patients. The hypothesis of their study was that PCT plasma kinetics over the first 72 hours of critical care improved mortality prediction of septic patients. The conclusion was that PCT kinetics over the first 72 hours of critical care provided prognostic information about ICU mortality and in-hospital mortality in patients with confirmed or likely sepsis.

One of the problems in the ICU is the need to differentiate patients with an inflammatory response from those with an infecting reaction. This is very prominent in respiratory tract infections [2]. Moreover, in lung

\footnotetext{
* Correspondence: jcruiz@vhebron.net

'Critical Care Department, Vall d' Hebron University Hospital, po de la Vall d'Hebron, 119-129, 08035, Barcelona, Spain

${ }^{2}$ Department of Medicine, Universitat Autònoma de Barcelona, Barcelona, Spain

Full list of author information is available at the end of the article
}

transplant, it is necessary to differentiate sepsis from acute humoral or cellular rejection when respiratory failure is developing. Assessment of early resolution is a secondary problem, associated with management decisions such as the need for an additional source control, a change of antibiotics, initiating adjunctive therapy or searching for complications. In these scenarios, PCT, Creactive protein and other biomarkers are objective variables to add to clinical assessment, becoming areas of active research, whereas genomics may provide additional clues in the future.

In medical practice, it is important to have evidence to assess the prognosis or to predict patient outcome. This is especially relevant in severe sepsis. PCT has been proposed as a specific biomarker of bacterial infections $[3,4]$ and has been related to the severity of sepsis [5]. The initial absolute peak of PCT in the inflammatory process induced by sepsis is early; it reaches plateau values at 6 to 24 hours and has a half-life around 24 to 36 hours [6].

The prognostic ability of initial concentrations of PCT in sepsis is controversial and while some studies $[7,8]$ find higher initial concentrations in non-survivors, others find no differences [9-12]. Significant changes induced by the therapeutic measures taken can occur even in patients with very high initial concentrations of PCT, so it is not always associated with poor prognosis. However, prognostic assessment based on follow-up of PCT levels may be better than evaluation of the initial levels of PCT.

In their study, Schuetz and colleagues [1] concluded that, in septic patients, PCT kinetics over the first 72 hours of critical care provided prognostic information beyond that from clinical risk scores and might assist physician decision-making regarding care intensification or early transfer from the ICU to the floor. For ICU and in-hospital mortality, a 72 -hour PCT decrease $>80 \%$ had a negative predictive value of $91 \%$, and no decrease or an increase in PCT over 72 hours had a positive predictive value of $48 \%$. This prognostic information was independent of initial 
severity scores (Acute Physiology and Chronic Health Evaluation Score IV and Simplified Acute Physiology Score II). As addressed by the authors, some limitations are relevant. It is a non-interventional study, including two independent cohorts of adults (with some imbalances) admitted to critical care units of different hospitals based on International Classification of Diseases edition 9 (ICD-9) and retrospective medical record reviews. Indeed, ICD-9 codes do not adequately identify cases of infection and sepsis, may underestimate certain infections and may overestimate severe sepsis due to the introduction of patients with organ dysfunction already present at the time of infection. Furthermore, it has been suggested that important differences in diagnostic coding strategies may be associated with each hospital [13].

The persistence of elevated PCT levels is indicative of poor prognosis. PCT kinetics could be a tool for assessing the evolution of severe sepsis and septic shock. Several papers have been published emphasizing the importance of measuring PCT kinetics. In patients with septic shock, Suberviola and colleagues [14] showed that a decrease in PCT levels at 72 hours was an independent marker of hospital survival. Karlsson and colleagues [11] showed that mortality in patients with severe sepsis was lower in those in whom PCT concentrations at 72 hours fell by more than $50 \%$ with respect to initial values. Assessment of PCT levels at an earlier time could also provide prognostic information. In this regard, Ruiz-Rodríguez and colleagues found that a decrease of PCT levels at 48 hours was a predictor of survival in patients with septic shock and multiorgan failure [15].

In summary, the study of Schuetz and colleagues [1] is welcome because it provides additional information on the potential contribution of biomarkers for the early identification of patients with poor prognosis. Predicting treatment failure depends on three issues: the antimicrobial therapy, the host and the bug. Therefore, further information is required regarding the interaction of these elements. Initial bacterial load in pneumococcal pneumonia has proven to anticipate the need for mechanical ventilation and vasopressor requirement [16]. Further research introducing newer molecular techniques of diagnosis plus biomarkers might serve to identify patients with sepsis candidates for pre-emptive adjuvant therapy.

Abbreviations

ICD-9: International classification of diseases edition 9; PCT: Procalcitonin.

\section{Competing interests}

JCR has received research support for ATOM. JR served in the speaker bureau for Brahms.

\section{Author details}

'Critical Care Department, Vall d' Hebron University Hospital, Po de la Vall d'Hebron, 119-129, 08035, Barcelona, Spain. ²Department of Medicine, Universitat Autònoma de Barcelona, Barcelona, Spain. ${ }^{3} \mathrm{CIBERES}$, Barcelona, Spain.

Published: 04 Sep 2013

\section{References}

1. Schuetz P, Maurer P, Punjabi V, Desai A, Amin DV, Gluck E: Procalcitonin decrease over 72 hours in US critical care units predicts fatal outcome in sepsis patients. Crit Care 2013, 17:R115.

2. Lisboa T, Selligman R, Diaz E, Rodriguez A, Teixeira PJ, Rello J: C-reactive protein correlates with bacterial load and appropiate antibiotic therapy in suspected ventilator-associated pneumonia. Crit Care Med 2008, 36:166-171.

3. Harbarth S, Holechova K, Froidevaux C, Pittet D, Ricou B, Grau GE, Vadas L, Pugin J, Geneva Sepsis Network: Diagnostic value of procalcitonin, interleukin-6, and interleukin-8 in critically ill patients admitted with suspected sepsis. Am J Respir Crit Care Med 2001, 64:396-402.

4. Simon L, Gauvin F, Amre DK, Saint-Louis P, Lacroix J: Serum procalcitonin and C-reactive protein levels as markers of bacterial infection: a systematic review and meta-analysis. Clin Infect Dis 2004, 39:206-217.

5. Jensen JU, Heslet L, Ensen TH, Espersen K, Steffensen P, Tvede MK: Procalcitonin increase in early identification of critically ill patients with a high risk of mortality. Crit Care Med 2006, 34:2596-2606.

6. Meisner M, Schmidt J, Huerrner H, Tschaikowsky K: The natural elimination rate of procalcitonin in patients with normal and impaired renal function. Intensive Care Med 1999, 26:212-216.

7. Clec'h C, Ferriere F, Karoubi P, Fosse J, Cupa M, Hoang P, Cohen I: Diagnostic and prognostic value of procalcitonin in patients with septic shock. Crit Care Med 2004, 32:1166-1199.

8. Christ-Cain M, Stolz D, Bingisser R, Müller C, Miedinger D, Huber PR, Zimmerli W, Harbarth S, Tamm M, Muller B: Procalcitonin guidance of antibiotic therapy in community-acquired pneumonia. Am J Respir Crit Care Med 2006, 174:84-93.

9. Claeys R, Vinken S, Spapen H, ver Elst K, Decochez K, Huyghens L, Gorus FK: Plasma procalcitonin and $\mathrm{C}$-reactive protein in acute septic shock: clinical and biological correlates. Crit Care Med 2002, 30:757-762.

10. Charles PE, Tinel C, Barbar S, Aho S, Prin S, Doise JM, Olsson NO, Blettery B, Quenot JP: Procalcitonin kinetics within the first days of sepsis: relationship with the appropriateness of antibiotic therapy and outcome. Crit Care 2009, 13:R38.

11. Karlsson S, Heikkinen M, Pettilä V, Alila S, Väisänen S, Pulkki K, Kolho E, Ruokonen E, The Finnsepsis Study Group: Predictive value of procalcitonin decrease in patients with severe sepsis: a prospective observational study. Crit Care 2010, 14:R205.

12. Meisner M, Tschaikowsky K, Palmaers T, Schmidt J: Comparison of procalcitonin (PCT) and C-reactive protein (CRP) plasma concentrations at different SOFA scores during the course of sepsis and MODS. Crit Care 1999, 3:45-50.

13. Gaieski DF, Edwards JM, Kallan MJ, Carr BG: Benchmarking the incidence and mortality of severe sepsis in the United States. Crit Care Med 2013, 41:1167-1174

14. Suberviola B, Castellanos-Ortega A, González-Castro A, García-Astudillo LA, Fernández-Miret B: Valor pronóstico del aclaramiento de procalcitonina, PCR y leucocitos en el shock séptico. Med Intensiva 2012, 36:177-184.

15. Ruiz-Rodríguez JC, Caballero J, Ruiz-Sanmartin A, Ribas VJ, Perez M, Rello J: Procalcitonin clearance as a severe sepsis and multiorgan dysfunction prognostic biomarker. Med Intensiva 2012, 36:475-480.

16. Rello J, Lisboa T, Lujan M, Gallego M, Kee C, Kay I, Lopez D, Waterer GW, DNA-Neumococo Study Group: Severity of pneumococcal pneumonia associated with genomic bacterial load. Chest 2009, 136:832-840.

\section{$10.1186 / \mathrm{cc} 12877$}

Cite this article as: Ruiz-Rodríguez and Rello: Predicting treatment failure in severe sepsis and septic shock: looking for the Holy Grail. Critical Care 2013, 17:180 